Reprod. Nutr. Dévelop., 1986, 26 (1 B), 385-386.

\title{
Variations du métabolisme de l'insuline chez le taurillon selon la nature du régime et l'état d'engraissement
}

\author{
Y. GEAY, J. GRIZARD $\left({ }^{*}\right)$ \\ avec la collaboration technique de Claire SORNET $\left(^{*}\right)$, Robert et Roland JALLER \\ Laboratoire de la Production de Viande, \\ (*) Laboratoire d'Etude du Métabolisme azoté et C.N.R.S. UA 414, \\ I.N.R.A., Theix 63122 Ceyrat.
}

Summary. Plasma insulin level and the disappearance from the circulation of injected insulin were studied in Friesian bulls at $300-400-500 \mathrm{~kg}$ of liveweight. Both preprandial and postprandial insulin concentration were higher in animals fed a high concentrate diet than a high roughage diet. Half-life of injected insulin was lower with the former diet than with the latter, suggesting that insulin secretion greatly increased with concentrate diet. No relationship was observed between insulin metabolism and fatness.

L'insuline intervient dans la limitation de l'ingestion chez le ruminant (Deetz et Wangsness, 1980). Une étude a été réalisée pour analyser l'importance de son action chez le taurillon selon la nature du régime et l'adiposité des animaux. Nous présentons les résultats concernant le catabolisme de l'insuline et son importance sur le déterminisme de l'insulinémie postprandiale.

Matériel et méthodes. Deux lots de 10 taurillons Pie Noirs ont reçu entre les poids de 175 et $500 \mathrm{~kg}$ un même régime (concentré $70 \%$ - foin de fétuque $30 \%)$ soit à volonté, soit en quantité limité $(80 \%$ du niveau précédent) afin d'induire au même poids deux états d'adiposité différents : I'un élevé (G) et l'autre moyen (M) appréciés par la taille des adipocytes (Robelin, 1982). Cependant aux poids de 300-400 et $500 \mathrm{~kg}$ les animaux de chaque lot ont reçu à volonté durant 3 semaines, pour moitié d'entre eux ( 5 du lot $G$ et 5 du lot $M$ ) un régime «fourrage " (foin $90 \%$ - concentré $10 \%$ ) et pour l'autre moitié un régime « concentré ") (foin $10 \%$ - concentré $90 \%$ ). Au cours de ces trois périodes où les aliments ont été distribués à 8-9 h, l'insulinémie a été mesurée à $7 \mathrm{~h} 30,9 \mathrm{~h} 30$ et $11 \mathrm{~h}$ 30. Le métabolisme de l'insuline a été estimé à partir de la mesure de sa concentration plasmatique $10,20,35$ et 60 min après l'injection, à $13 \mathrm{~h}$, d'insuline bovine par voie jugulaire $(5 \mu \mathrm{g} / \mathrm{kg}$ de poids vif.

Résultats. L'insulinémie préprandiale est significativement plus élevée $(\mathrm{P}<0,05)$ avec le régime " concentré " qu'avec le régime "fourrage », quel que soit l'état d'adiposité chez tous les animaux à 300 et à $400 \mathrm{~kg}$ et chez ceux du lot (M) à $500 \mathrm{~kg}$ (fig. 1). La distribution de la ration entraîne une élévation de l'insulinémie chez presque tous les animaux qui reçoivent le régime "concentré " alors qu'elle ne change pas celle des animaux recevant le régime "fourrage ».

L'insulinémie est fortement accrue 10 min après l'injection chez tous les animaux $(P<0,01)$. Elle diminue ensuite très rapidement et atteint, 60 min après, 
une valeur proche de la valeur observée avant l'injection (fig. 1). Quelle que soit l'adiposité des animaux, l'insulinémie 10 et 20 min après injection est significativement plus élevée $(P<0,05)$ chez les animaux au régime concentré à $300 \mathrm{~kg}$ et plus faible à $500 \mathrm{~kg}$ que chez ceux au régime fourrage. Elle est indépendante du régime à $400 \mathrm{~kg}$.

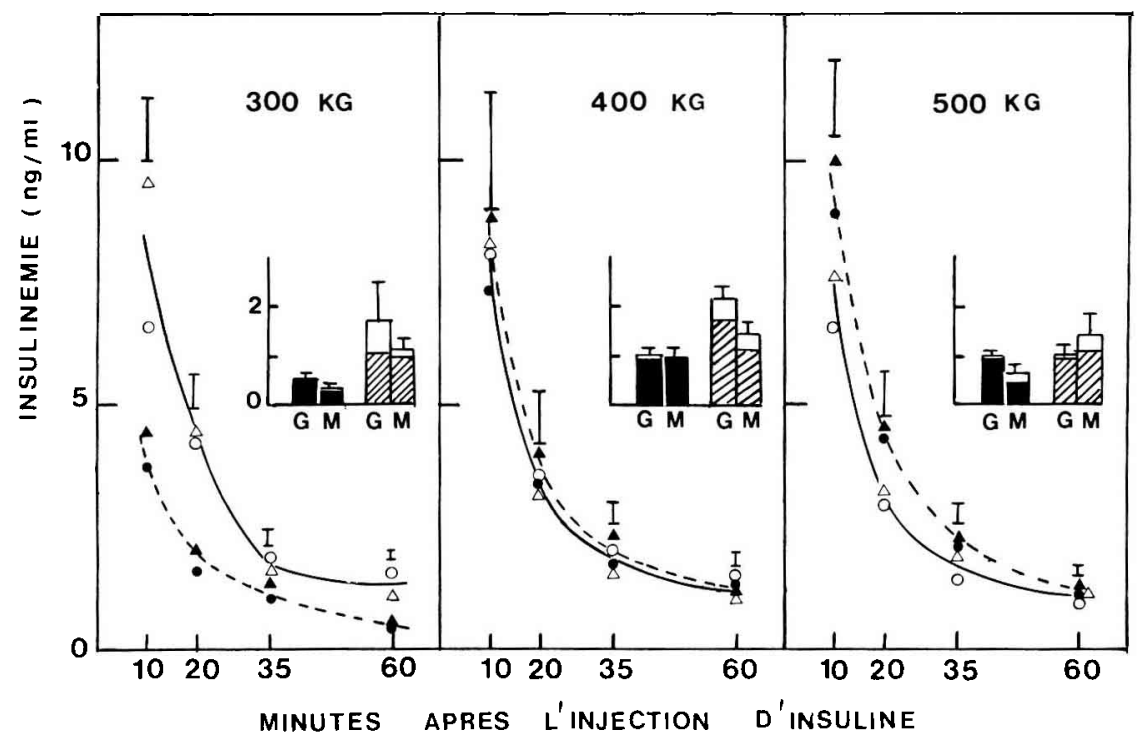

FIG. 1. - Insulinémie avant (histogrammes insérés) et après injection d'insuline des taurillons recevant

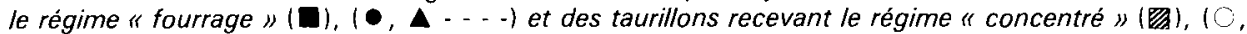
$\Delta-1$. Dans chaque histogramme la surface sombre $\square$ V représente l'insulinémie préprandiale, la surface claire $\square$ est l'élévation postprandiale $(11.30 \mathrm{~h})$. Animaux du lot $\mathrm{M}(\boldsymbol{\Delta}, \triangle)$ et du lot $\mathrm{G}(\bullet, O)$. Ecarts types de la moyenne $(T)$.

Le logarithme de la différence (insulinémie après injection - insulinémie avant injection) diminue linéairement en fonction du temps depuis l'injection durant les 35 premières minutes. Quels que soient le poids et l'adiposité des animaux, la pente de cette droite est environ 2 fois plus forte avec le régime concentré qu'avec le régime fourrage. II s'ensuit que la demi-vie de l'hormone injectée est beaucoup plus courte $(42 \%)$ avec le régime concentré.

La nature du régime distribué a donc une influence importante sur le métabolisme de l'insuline des taurillons. Un régime à forte proportion de concentré, se traduit, comparativement à un régime à forte proportion de fourrages, par une élévation des insulinémies pré- et post-prandiale et du catabolisme de l'hormone. Cela signifie que la sécrétion d'insuline est fortement accrue. En revanche, dans les conditions de l'expérience, l'adiposité des animaux n'a eu que peu d'effets sur l'insulinémie.

Deetz L. E., Wangsness P. J., 1980. Effect of intrajugular administration of insulin on feed intake, plasma glucose and plasma insulin of sheep. J. Nutr., 110, 1976-1982.

Robelin J., 1982. A note on the estimation in vivo of body fat in cows using deuterium oxide or adipose-cell size. Anim. Prod., 34, 347-350. 